\title{
INDUSTRISAMFUNN OG KULTURARV
}

\author{
Randi Bårtvedt
}

Vestnorsk Industristadmuseum representerer ein ny type museum i Noreg; eit museum som kombinerer industribistorie med sosialhistorie, og kor landskap og kultur er delar av museumskonseptet. Eg vil presentera museet vart og gje dome på utfordringar ved a skapa eit industrimuseum som skildrar daglegliv og arbeidsliv på 1900-talet, var eiga tid.

Som leiar ved Vestnorsk Industristadmuseum arbeider eg ikkje for ein interessert minoritet, men for alle folk på heimstaden min Odda, forstaden Tyssedal og dei omliggjande distrikta. Mi oppgåve er å understrekja kor viktig det er å kjenna historia vår, røtene våre og identiteten vår, slik at vi også kan forstå andre folk. Eg er sjølv medlem av dette lokalsamfunnet, men som yrkjesmenneske er eg betalt for å ta vare på kulturarven og dokumentera samtida. Eg har fătt i oppgåve å byggja eit heilt nytt museum frå grunnen av. Det har vore interessant å arbeida så hardt for det eg trur på; ideen om folkemuseet og dets mål: utdanning.

I 1985 vart eg engasjert av Odda kommune for å utreia grunnlaget for å etablera eit museum i Odda. Eg var då nyutdanna etnolog og fengsla av ideen om økomuseet, museet som tar del i lokalsamfunnet og engasjerer seg i politiske spørsmål. Slik kan eit museum gje rom for aktivitet, involvera og interessera folk og engasjera dei i eigne omgjevnader, samtida og historia. Historia eksisterer ikkje i museet åleine, men mellom folka i eit samfunn.

Eg vil no freista å fortelja om det å byggja opp eit industri- og sosialmuseum $\mathrm{i}$ eit lite samfunn. Arbeidet starta som sagt ved eit skrivebord i 1985.

\section{ODDA OG TYSSEDAL}

I desse ti åra har eg hovedsakeleg arbeidd med menneske og deira haldningar til eige samfunn og eigen historie. Odda-samfunnet består av eit dramatisk landskap, vasskraft som ein nøkkelressurs, moderne teknologi og tre svære fabrikkar som produserer sink, titanoksydslagg/råjern og kalsiumkarbid/dicyandiamid. Staden har ikring 8000 innbyggjarar. Tyssedal ligg $6 \mathrm{~km}$ frå Odda sentrum og var rundt århundreskiftet så og seia ei sprekke i fjellet med to gardar. I 1906 endra Tyssedal seg til å bli den største anleggsplassen i landet. I 1908 var Tyssedal ein småby med ein stor kraft- 
stasjon som hjarta. Gjennom vasskraft og elektrisitet blei Tyssedal og Noreg eit moderne, velståande samfunn. Dette er historia om eit gardssamfunn og ei internasjonalt kjent turistperle som endra seg over natta til å bli ein industristad. Det er historia om modernisering og historia om dei kvinnene, mennene og borna som flytta til Odda.

Samfunnet er råmaterialet for Vestnorsk Industristadmuseum. Museet har gradvis vakse til det det er idag, lokalisert i eit levande industrisamfunn der båtar frå heile verda kjem og går med råmaterial og eksportvarer. Eit samfunn basert på moderne smelteverk og kraftproduksjon.

Idag er museet eit av dei største i Noreg på temaet vasskraft. Vi har utstillingar om mennesket $\mathrm{i}$ industrisamfunnet, miljøproblema si historie og teknologihistorie. Vi har arkiv som inneheld informasjon om organisasjonar og fabrikkar og som blir brukt i forskinga. Vidare har vi ein filmsal med biletspel som er spesiallaga for å skildra historia vår, og tre arbeidarbustader der den eine viser forskjellege interiør heilt opp til 1990-åra.

Museet arrangerer også turar med guide i fotspora til arbeidarpionerane og til industrimonumenta innafor og utafor fabrikkane og kraftstasjonen.

Hardanger er internasjonalt kjend som eit idyllisk turistområde. Isbreane, fossefalla, den blågrøne fjorden og fruktbløminga gjer landskapet i Hardanger til eit romantisk dikt.

Tyssedal i Hardanger har ein annan tone og rytme. Det er eit skiftarbeidande samfunn, ei bygd med smelteverk, varme og elektrisitet.

\section{A SKAPA EIT ØKOMUSEUM}

Gjennom etnologi-studiet vart eg kjend med ideen om okomuseet; det à bevara bygningar og gjenstandar på deira opphavlege område og omgjevnad istaden for å flytta alt til ein museumsbygning eller eit museumsomrade. Dessutan å dokumentera og forklara korleis menneske takla naturen og dagens samfunn. No hadde eg høve til å skapa eit økomuseum, ein plass kor folk kunne bli oppmuntra til å engasjera seg i historia, i lokalsamfunnet og samtida. Etter mi meining er eit moderne museum berre interessant når publikum - dei besøkjande - engasjerer seg og er deltakarar, og konservatoren har rolla som ein profesjonell rådgjevar.

Lat oss no sjå på det som skjedde i Odda, då vi tok steget frå ein ide til hardt arbeid.

Som etnolog arbeider eg utifra eit holistisk syn på samfunnet. Industristadmuseet skulle samla og visa alle sider av eit miljø og intervjua ulike grupper i lokalsamfunnet. Folk skulle få fortelja om livshistoria si, om heimen, arbeid og fritid. Museet skulle dokumentera kjensler, tankar og draumar.

Då eg var einaste tilsette, blei det naudsynt å engasjera frivilleg hjelp, som til dømes fagarbeidarar frå smelteverket, husmødrer og born, slik at dei kunne fortelja om liva sine og visa museet kva vi kunne bruka i utstillingar.

Det første museumsbyggjet vårt var ein arbeidarbustad med eitt rom og kjøken på kvar familie, og fire familiar i kvart hus. Vi redda dette huset frå å bli rive, og vi byrja å samla møblar, kle og fotografi. Mange folk kom for å sjå kva dei kunne gje for å skapa eit opprinneleg interiør. 


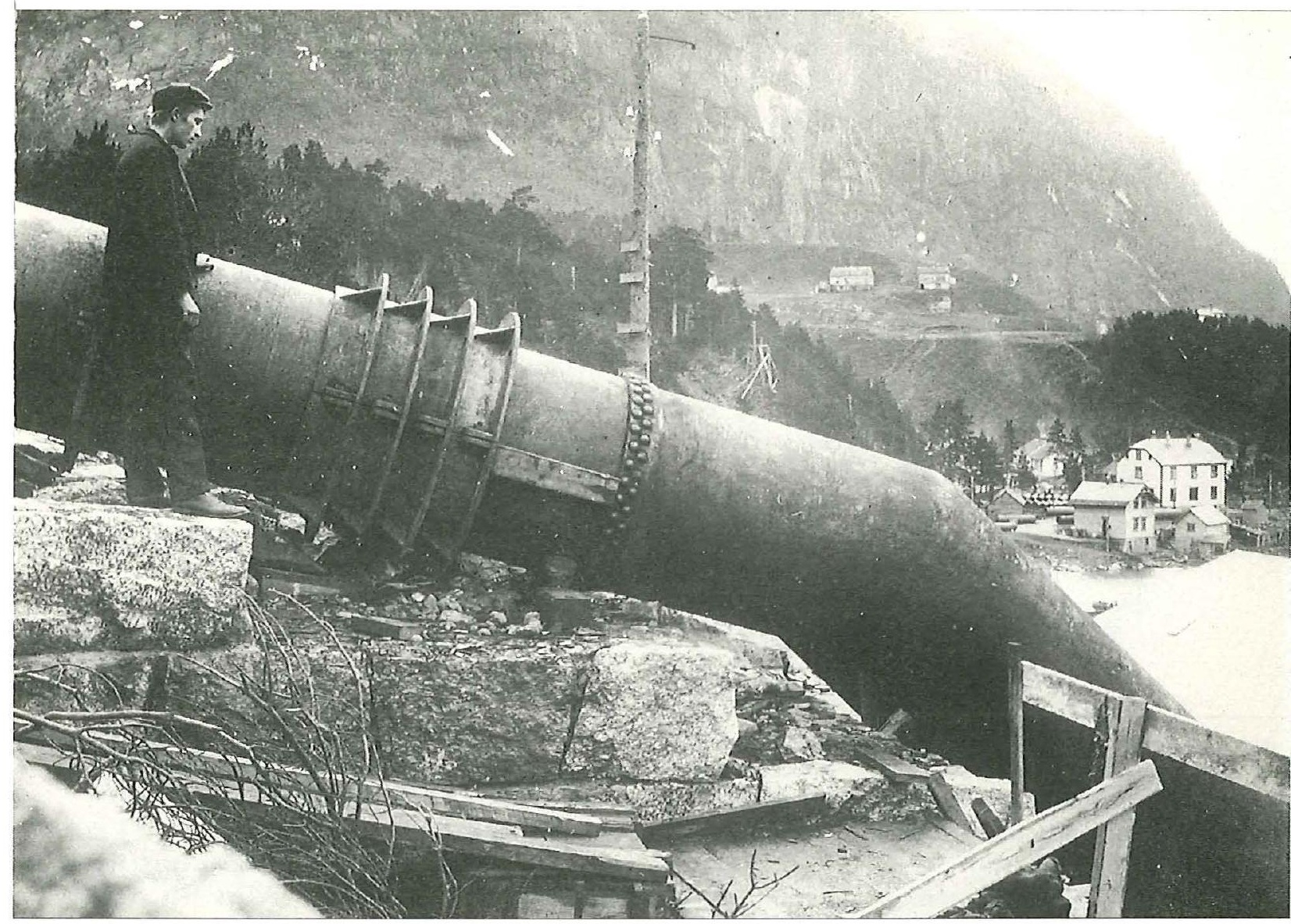

Kraftutbygginga $i$ Tyssedal var eit dramatisk inngrep som over natta endra eit lite jordbrukssamfunn og ei internasjonalt kjent turistperle, til ein industristad. Foto fra ca. 1908. Arkiv: A/S Tyssefaldene.

Gradvis blei vi istand til å fortelja historiene til namngjevne familiar som hadde budd i huset i forskjelege tidsbolkar, ein i frå 1920-åra, ein i frå 1930-åra, ein i frå 1950-åra osv. Vi fortalde til dømes historia om herr Ingebrigtsen, som var smed på fabrikken. Han flytta frå Bergen til Odda med familien sin, kone og to born, og to til blei fødd $\mathrm{i}$ bustaden som han var heldig å få leiga av fabrikken. Dei flytta til Odda fordi lønene var mykje høgare her enn i byen. Vi fortalde og kva som skjedde med familien da fabrikken som var eigd av British Sun Gas Co., gjekk konkurs og 1000 menn måtte gå arbeidsledige i fire år på 1920-talet før fabrikken blei refinansiert. Vi skildra arbeidet til ei mor, korleis ho måtte laga alt sjøl og jobba som vaske- kone på skulen i tillegg. Vi skildra lukke og sorg i familien, som til dømes kor tungt det var då den 14 år gamle sonen deira døydde og klassen hans kom for å ta farvel, og då broren Willy tjente sine første pengar for å kjøpa seg ein dress til konfirmasjonen, og seinare då han sparte pengar for å kjøpa seg ein radio (1938) slik at han kunne få siste nytt om borgarkrigen i Spania.

I byrjinga sa folk: "Eg har ikkje noko interessant å fortelja museet», men heldigvis fortalde nokre av dei historia si likevel. Til slutt vart dei stolt av kva dei fortalde alt ned til den minste detalj som ved første augekast kunne virka lite viktig. Vi samla forskjellige livshistorier i ei bok som blei illustrert med bilder fra deira private 
70 album. Lesarane fekk verkeleg læra å kjenna vesle Willy som gut i 1920 -åra. Alice fortalde om sin oppvekst, som dottera til ein av direktørane. Alt blei så nært at det var mogleg å kjenna seg igjen. Ein fekk sjå sambandet mellom gruppene i lokalsamfunnet i ei tid då industrien var ung.

Gjennom intervjua fekk museet 200 historieforteljarar og vener av museet. Nokre av informantane samla og inn ting for oss. Dei opplevde museet som sin eigedom.

Då vi opna industristadmuseet var det omtrent 1000 besøkjande i arbeidarbustaden på ei veke. Vi hadde også produsert eit biletspel som heiter «Borna på Bakke», som skildra levekåra i nabolaget rundt arbeidarbustadane. Det blei veldig populært, og i dag er biletspel ein av spesialitetane våre.

Lite eller ingenting hadde blitt gjort for å samla historia til industristaden Odda før dette museumsprosjektet starta. Vi danna difor forskjellige arbeidsgrupper for å få gjort innsamlingsarbeid. Ei gruppe byrja å samla arbeidsutstyr på fabrikken Norzink for å visa arbeidet i ein stor fabrikk. Slik vart yrkesgrupper involverte i eigen historie. Mi oppgåve var å gje råd, koordinera og oppmuntra til museumsarbeidet. Til dømes lukkast vi å dokumentera den siste arbeidsdagen i den gamle produksjonshallen til Norzink ved hjelp av fotografi og lydbandopptak.

Litt etter litt blei museet ein realitet og ein positiv faktor i Oddasamfunnet, og var på den måten med på å styrka lokal-identiteten deira. Det var ikkje tilfellet då vi starta med museumsarbeidet. Før følte folk frå Odda seg ofte diskriminerte og trudde at historia deira hadde liten verdi. Det var rett og slett vanskeleg å fortelja til folk frå hovudstaden at du kom frå Odda, som i aviser var framstilt som ein forferdeleg plass med tungindustri, politisk radikale menneske og kravmentalitet.

Etter tre år med arbeid betalt av dei lokale styresmaktene, fagorganisasjonane, kraftselskapet og fabrikkane, blei Vestnorsk Industristadmuseum etablert med tre fast tilsette, ein konservator og leiar, ein arkivar og ein sekretær. Frå då av fekk museet også årlege løyvingar frå staten.

Museet fekk mykje velvilje fra lokalsamfunnet og mottok prosjektmidlar frå staten for pionerarbeid på området dokumentasjon av norsk industrihistorie. Vi ordna og katalogiserte også dei fyldige arkiva på tre fabrikkar og kraftselskapet slik at ein sikra bevaringa og la til rette for forsking. Gradvis lukkast vi også med å ta vare på dei tre arbeidarbustadene og starta i 1990 på eit mykje oversett felt, med arkitektur og teknologihistorie.

Museet engasjerte seg også i miljøvernhistorie. Det var eit kjenslevart tema for mange personar i lokalsamfunnet. I dag, når mange av problema er løyste, blir museet stadig spurd om å visa alle sider ved industrien, også miljøproblema. Vi skildrar også prosessen med å rensa fjorden igjen, og tiltaka som blei satt i verk av den lokale industrien og styresmaktene. Museet produserte eit biletspel om forureiningsproblema, og vi har også intervju og fotografi frå dette temaet.

Det må nemnast at vi ikkje er eit reint teknisk og industrielt museum. Vi prøver å skildra alle sider ved eit samfunn, og då er det naturleg at vi også presenterer den sosiale historia. 


\section{STATUS VED MUSEET I DAG}

Dei lokale politikarane og ordføraren er inneforstått med verdien av det arbeidet som museet gjer. Dei er $100 \%$ bak forslaga våre og gjev oss så mykje midlar som dei kan, men det blir ikkje nok til å dekkja kostnadane ved det arbeidet som vi utfører. Det er dyrt å ta vare på industrihistoria. Odda er ein viktig stad i norsk industrisoge. Monumenta her har stor nasjonal betydning, og derfor tykkjer vi at staten må løyva meir pengar i framtida.

Tyssedal kraftstasjon kan daterast tilbake til 1908 og var ein av dei største i Noreg og Europa då den blei bygd. Det er derfor ikkje å undrast over at nøkkelordet $\mathrm{i}$ vår aktivitet er "Med vatn som ein nøkkelressurs». Saman med lokale politikarar tok vi initiativet til å få kraftstasjonen og røyrgata på lista for freda anlegg. Kraftselskapet produserer ikkje hydro-elektrisk kraft lenger $\mathrm{i}$ denne bygninga og ville fjerna delar av det unike maskineriet frå 19081989 for å bruka plassen til fiskeoppdrett eller andre kommersielle føretak.

Etter mi meining er Tyssedal kraftstasjon unik også fordi den er hjarta i eksistensen av dette samfunnet. Det har vore avhengig av elektrisitet i dei siste 90 åra.

I dag vil dei sentrale styresmaktene freda den midtre delen av kraftstasjonen med interiør og la resten bli brukt til kommersielle føremål bestemt av kraftselskapet. Men museet og dei lokale politikarane vil freda heile bygninga. Den endelege avgjera er enno ikkje tatt.

Industristaden Tyssedal blei planlagd av leiande arkitektar i Noreg, og vi kan framleis lesa plassen som ei bok med eit klart mønster av klasseskilje. Her er bustader for funksjonærar på eit område, for vanle- ge arbeidarar på eit anna, og på dei beste plassane budde direktørane. Fabrikken, skulen, forsamlingslokale, alt blei nøye planlagt og er av arkitektonisk høg verdi.

I 1990 ville dei lokale styresmaktene riva eit hus i eit bustadområde, ein gong kjent som eit godt nabolag der eigarane konkurrerte om kven som hadde den gjevaste hagen. Museet gjekk imot rivinga, og med økonomisk og profesjonell hjelp frå Riksantikvaren blei huset redda og restaurert. Idag finst ein verneplan for området som er ei av dei eldste hagebyane i Noreg. I dette tilfellet var det også naudsynt å visa politikarane kor viktig det var å restaurera heile bustadområdet. Igjen fungerte museet, saman med støtte utanfrå, som ein rådgjevar med omsyn til korleis ein skulle ta vare på den lokale kulturarven. Som ein vidareføring av dette starta vi opp Tyssedalprosjektet som har som mål å bevara og utvikla heile staden, og ikkje berre interiøret i den gamle kraftstasjonen og røyrgata. På denne måten prøver vi også å gjera Tyssedal meir interessant og tilgjengeleg for turistar, lokalbefolkninga og skuleelevar. Eit spesielt turist- og kulturprogram har som mål å skapa nye arbeidsplassar på dette område. Dei siste tre åra har Odda kommune vore ansvarleg for dette prosjektet og bevilgar pengar til arbeidet.

Idag trur eg at dei fleste er stolt over å ha eit museum i Odda, og det er eit viktig resultat av arbeidet vårt. Framleis har museet ikkje greidd å auka talet på besøkjande, men her må det nemnast at vi er inne $\mathrm{i}$ vårt første år $\mathrm{i}$ eit restaurert administrasjons- og museumsbygg. No blir målet å gjera museet enno meir tilgjengeleg for besøkjande. Nokre av «konkurrentane» til musea er til dømes ymse «opple- 
72 vingssenter» som har kommersielle føremål, og ikkje nødvendigvis utdanningsføremål. A utdanna folk er eit meir usynleg mål der resultata vanskeleg let seg talfesta. På lang sikt vil mål som det å visa autensitet, visa eit levande samfunn og sikra vår kulturarv bli akseptert som viktig.

Som leiar av museet kjempar eg konstant med å få nok pengar til å gjera ein skikkeleg og profesjonell jobb. Eg tykkjer det er på høg tid å annerkjenna den "gamaldagse» ideen om folkemuseet som ein utdanningsinstitusjon og ikkje ein kommersiell institusjon. Etter mi meining treng vi sterke lokale museum, som har lokalsamfunnet som eit grunnlag og forskingsområde for å dokumentera individa si historie og deira omgjevnader $\mathrm{i}$ eit mikroperspektiv. I vårt tilfelle blir det å bevara og forklara historia til eit industrisamfunn som eit kapittel og ei pågåande forteljing i den vestlege verda. Men samtidig er det også ei interessant side ved den nasjonale historia vår i eit makroperspektiv. Ein fordel ved museet vårt er då at det er nært til brukarane og informantane.

\section{SUMMARY}

An industrial community and its heritage

This paper was given at the Seminar on Museums and Museology in Norway and Scandinavia, ICOFOM Stavanger July 2, 1995. It deals with the process of building an industrial and social museum from scratch in a small community. The author is a curator and director of the museum today and has been involved in the museum work from the beginning in 1985. At first the main task was to collect photos and interviews and to restore a workmen's dwelling with its original interior at different time periods. Today the museum is located in an historic building from 1914 and has expanded its activities with i.a. historical archives from the factories, books, slide shows and guided tours in the old hydro electric power station. The museum policy is to present society from a holistic point of view, both in terms of history and contemporary issues such as pollution problems. An important aim here is to use the museum as an educational institution for the local inhabitants, pupils and students, but also as a tourist attraction in an important tourist resort of our country.

The paper is available in English.

Randi Bårtvedt er utdanna etnolog frà Universitetet $i$ Bergen, styrar og konservator ved Vestnorsk Industristadmuseum, Odda $i$ Hardanger fra 1984. Adr: Vestnorsk Industristadmuseum, Postboks 89, N-5770 Tyssedal Fax +47-53644277 